\title{
A mortality cohort study among workers in a graphite electrode production plant in Italy
}

\author{
D F Merlo, S Garattini, U Gelatti, C Simonati, L Covolo, M Ceppi, F Donato
}

Occup Environ Med 2004;61:e9 (http://www.occenvmed.com/cgi/content/full/61/2/e9)

See end of article for authors' affiliations

.....................

Correspondence to: Dr D F Merlo,

Environmental

Epidemiology and Applied Biostatistics, Istituto Nazionale per la Ricerca sul Cancro, Largo Rosanna Benzi 10, 16132 Genova, Italy; franco.merlo@istge.it

Accepted

5 September 2003
Background: Graphite electrode manufacturing workers are exposed to coal tar and its volatiles containing a variety of polycyclic aromatic hydrocarbons (PAH), silica and graphite dusts, and asbestos. Aims: To investigate mortality from cancer and other diseases among workers in a graphite electrode production plant in Italy.

Methods: A total of 1291 males actively employed between 1 January 1950 and 31 December 1989 who had worked at the plant for at least one year were studied. The follow up extended from 1950 to 1997. Standardised mortality ratios (SMR) and their $95 \%$ confidence intervals (Cl) were computed using mortality rates for the Italian and regional male population.

Results: Excess mortality was observed for all causes (SMR 1.44, Cl 1.32 to 1.56), all cancers (SMR 1.27, $\mathrm{Cl} 1.07$ to 1.50), liver cancer (SMR 4.19, Cl 2.68 to 6.23), silicosis (SMR 66.39, Cl 52.56 to 82.7), and cirrhosis and other chronic diseases of the liver (SMR 1.87, Cl 1.31 to 2.59) in comparison with the national male population. When regional rates were used to calculate the number of expected deaths, SMRs remained higher for silicosis (SMR 57.32, 42.11 to 76.22), and liver cancer (SMR 2.57, 1.57 to 3.97 ). Mortality from silicosis was increased in workers hired at young ages ( $<25$ years, SMR $81.79 ; 25-$ 34 years, SMR 82.73), and in workers aged $<45$ at death (SMR 333.3, $\mathrm{Cl} 159.8$ to 613 ). Mortality from liver cancer increased threefold (SMR 3.11, Cl 1.78 to 5.05) in workers with more than 10 years of employment at the plant during the manufacture of Karbate products.

Conclusions: Results support the association between excess mortality from silicosis and occupational exposure to siliceous sands experienced during graphite electrode manufacturing. The observed excess mortality from liver cancer is compatible, to some extent, with exposures that may have occurred during the manufacture of phenolic and furfuryl resins treated products, although a role of lifestyle factors and viral infections cannot be excluded.
O nly a few small cohort studies have been carried out among workers in carbon and graphite electrode manufacturing plants. ${ }^{1-6}$ Their findings concerning overall mortality and mortality from specific causes, including respiratory diseases and site specific cancers, are conflicting and the scientific evidence of any health risk remains inconclusive. Occupational exposure to coal tar pitch, polycyclic aromatic hydrocarbons (PAH), and siliceous sands have been reported to occur during carbon and graphite electrode manufacturing. The International Agency for Research on Cancer, has classified coal tar pitches ${ }^{7}$ and crystalline silica (inhaled in the form of quartz or christobalite), ${ }^{8}$ as carcinogenic agents to humans (group 1) and PAH, including benzo[a]pyrene, benz[a]anthracene, and diben$\mathrm{z}[\mathrm{a}, \mathrm{h}]$ anthracene as probable carcinogenic agents to humans (group 2A). ${ }^{7}$ Increased risk of lung and bladder cancers has been reported among workers occupationally exposed to the above compounds, although the epidemiological evidence on the role of $\mathrm{PAH}$ remains inconclusive. ${ }^{4}$ We aimed to investigate overall and site specific mortality from cancer and other diseases among workers employed at a graphite electrode production plant in Italy.

\section{MATERIALS AND METHODS}

The plant

The plant, located in the province of Brescia, Lombardy Region, in North Italy, manufactured various graphite products, mostly graphite electrodes for the iron and steel industry, between 1929 and 1994, when it closed down. Electrode production ranged between 1000 tons/year during the early 1930s and 25000 tons/year during the mid-1970s. The workforce at the plant rose from 100 subjects during the early years of activity up to 870 blue collar workers in 1970, excluding white collar workers who were employed at the main offices in Milan. The raw materials historically used were coal tar pitch, petroleum derived coke, and additives (mainly iron oxide, mineral oils, and stearic acid). Figure 1 shows the main stages in the electrode production process. In the first step of this process, the raw materials were mixed at a temperature of about $180^{\circ} \mathrm{C}$, charged in an extrusion press, and extruded at a temperature of about $100^{\circ} \mathrm{C}$. The rods were then cut, cooled by immersion in cold water, and baked at $850-1200^{\circ} \mathrm{C}$ in pit furnaces fed by naphtha and filled with a coke and siliceous sand stuffing. After baking, the electrodes were impregnated under pressure with liquid pitch. The last step of the production was graphitisation in electric furnaces. The furnaces were loaded and unloaded using hand operated equipment, which involved intense exposure to heat, dust, smoke, and gases. The electrodes were packed both horizontally and vertically, stowed by coke and siliceous sand, and covered with aluminium and/or iron silicate. There were three graphitisation departments. The first department was operative from the opening of the plant until 1981. Until 1974, it included the impregnation process that contributed significant exposure to smoke and gases produced by the

Abbreviations: $\mathrm{Cl}$, confidence interval; $\mathrm{PAH}$, polycyclic aromatic hydrocarbon; SIR, standardised incidence ratio; SMR, standardised mortality ratio 


\section{Main messages}

- The study found an increased mortality for silicosis and liver cancer in workers engaged in the production of graphite rods and phenolic and furfuryl resins treated products.

heating of the pitch. The second graphitisation bay became operative in 1957 and had the same kind of manufacturing technology and furnaces as the oldest department. In 1981 a third, much more modern, graphitisation system became operative: the electrodes were loaded in the electric furnace horizontally and in line, with the stuffing of coke grit. The siliceous sand used for stowage was replaced with rice husks in 1967. The last step in the rod production consisted of finishing the electrodes using industrial machines. Other manufacturing processes besides electrode production were performed at the plant. Anode manufacturing (plates and round bars) for the chemical industry was introduced in 1940 and continued until 1974. The production of Karbate tubes for heat exchangers used in distillation towers by the chemical industry and bricks was started in 1959 and discontinued in 1976. These graphite products, manufactured according to the rod production process described previously, were soaked in phenolic and furfuryl alcohol based resins (instead of pitch), to enhance corrosion resistance to weak acids. This production may have resulted in exposure to phenolic compounds, furfuryl alcohol, and furfural.

\section{Population}

We recruited 1291 male workers actively employed between 1 January 1950 and 31 December 1989 who had worked at the plant for at least one year. We collected information on date of hire and date of resignation for each worker from the registers of factory employees. Non-production workers (that is, office workers) were not included in the cohort. No women worked on the production lines. Since neither qualitative nor quantitative data were available on the level of exposure to specific chemicals inside the plant according to the work performed, all workers were considered as equally exposed to airborne pollutants including PAHs, silica dusts and silicates, and chemical compounds released during the manufacture of phenolic and furfuryl resin treated products. Information on lifestyle variables, including smoking and drinking habits, was not available. The follow up spanned from 1 January 1950 to 31 December 1997. Vital status at the end of the follow up and the causes of death for deceased subjects were retrieved by consulting the municipality and local health unit registers. The causes of death were coded according to the 9th revision of the International Classification of Diseases (ICD-9).

\section{Data analysis}

Person-years of observation stratified by five-year age groups and calendar periods were computed to calculate the expected deaths, using quinquennial age and calendar specific death rates of the Italian male population for the entire follow up period 1950-97. Moreover, since the plant is located in a area with a high mortality for cancer, especially liver cancer, non-malignant respiratory diseases and liver cirrhosis, ${ }^{9}$ regional rates (available for the calendar period 1970-97) were used to compute the expected number of deaths from selected causes, under the assumption that regional rates are more suitable for the comparison with the study cohort. Standardised mortality ratio point estimates (SMR) and their 95\% confidence intervals (CI) were

\section{Policy implications}

- The relation between exposure to furfuryl alcohol precursor, furfural, and the reported liver toxicity is supported by controlled animal studies; further epidemiological research is needed.

computed assuming a Poisson distribution ${ }^{10}$ and using the STATA statistical package. ${ }^{11}$ For selected causes of deaths, SMR analysis was performed according to the distribution of age at hire, age at death, time since hire, and duration of employment at the factory.

\section{RESULTS}

A total of 35167 person-years of observation in the cohort was included in the statistical analysis. Of the 1291 workers included in the cohort, 747 (57.9\%) were still alive at the end of the follow up, 541 (41.9\%) had died, and only $3(0.2 \%)$ were lost to follow up. Cancer accounted for $26 \%$ of all deaths, and diseases of the circulatory and respiratory system for $23.3 \%$ and $19.9 \%$, respectively. There were 79 (73\%) deaths from silicosis out of 108 deaths from respiratory tract diseases.

Table 1 shows the number of observed and expected deaths, calculated by using the national mortality rates for Italian men, the corresponding SMRs and their 95\% CIs. Excess mortality was observed for all causes of death (541

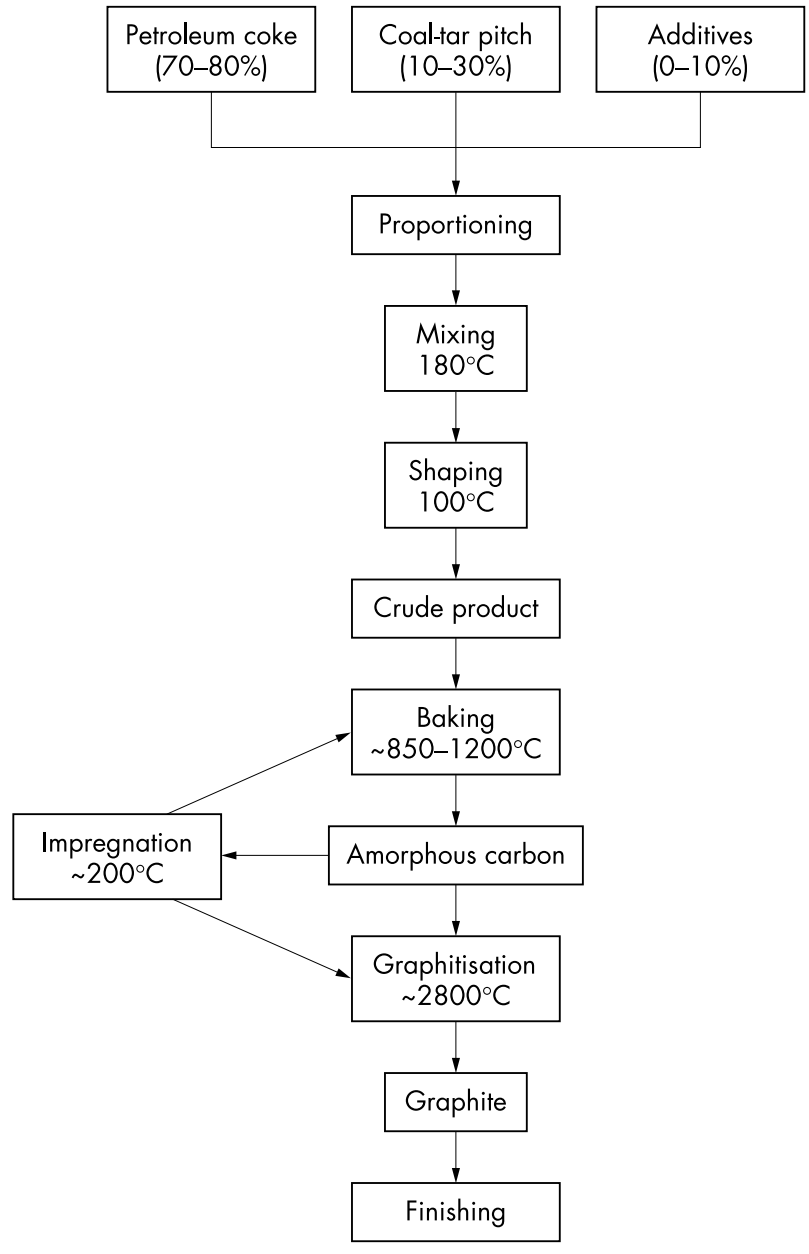

Figure 1 The manufacturing processes. 
Table 1 Mortality from specific causes among graphite electrode manufacturing workers

\begin{tabular}{|c|c|c|c|c|}
\hline Cause of death (ICD 9th) & $\begin{array}{l}\text { Observed } \\
\text { deaths }\end{array}$ & $\begin{array}{l}\text { Expected } \\
\text { deaths }\end{array}$ & SMR & $95 \% \mathrm{Cl}$ \\
\hline All causes (001-999) & 541 & 376.19 & 1.44 & 1.32 to 1.56 \\
\hline Infectious and parasitic diseases (001-139) & 6 & 7.11 & 0.84 & 0.31 to 1.84 \\
\hline Malignant neoplasms (140-208) & 141 & 110.95 & 1.27 & 1.07 to 1.50 \\
\hline Lips, mouth, and pharynx (140-149) & 8 & 3.8 & 2.10 & 0.91 to 4.14 \\
\hline Oesophagus (150) & 6 & 2.74 & 2.19 & 0.8 to 4.77 \\
\hline Stomach (151) & 17 & 13.36 & 1.27 & 0.74 to 2.04 \\
\hline Colon (153) & 4 & 5.89 & 0.68 & 0.18 to 1.74 \\
\hline Rectum (154) & - & 3.35 & 0.00 & 0.00 to 0.89 \\
\hline Liver (155) & 24 & 5.73 & 4.19 & 2.68 to 6.23 \\
\hline Pancreas (157) & 3 & 4.06 & 0.74 & 0.15 to 2.16 \\
\hline Larynx (161) & 5 & 3.8 & 1.32 & 0.43 to 3.07 \\
\hline Lung (162) & 32 & 32.89 & 0.97 & 0.67 to 1.37 \\
\hline Pleura (163) & - & 0.63 & 0.00 & 0.00 to 4.73 \\
\hline Bone and articular cartilage (170) & 2 & 0.9 & 2.22 & 0.27 to 8.04 \\
\hline Connective tissue (171) & 1 & 0.2 & 5.04 & 0.13 to 28.1 \\
\hline Melanoma (172) & 1 & 0.73 & 1.37 & 0.03 to 7.63 \\
\hline Prostate (185) & 10 & 5.6 & 1.78 & 0.86 to 3.28 \\
\hline Bladder (188) & 5 & 4.61 & 1.08 & 0.35 to 2.53 \\
\hline Kidney (189) & 4 & 2.19 & 1.83 & 0.50 to 4.68 \\
\hline Brain (191) & 2 & 2.28 & 0.88 & 0.11 to 3.16 \\
\hline Lymphomas (200-202) & 3 & 3.13 & 0.96 & 0.20 to 2.80 \\
\hline Leukaemia (204-208) & 1 & 3.39 & 0.30 & 0.01 to 1.65 \\
\hline Diseases of the circulatory system (390-459) & 126 & 143.08 & 0.88 & 0.73 to 1.05 \\
\hline Diseases of the respiratory system (460-519) & 108 & 26.75 & 4.04 & 3.31 to 4.87 \\
\hline Silicosis $(500,502)$ & 79 & 1.19 & 66.39 & 52.56 to 82.74 \\
\hline Diseases of the digestive system (520-579) & 49 & 30.15 & 1.63 & 1.20 to 2.15 \\
\hline Liver cirrhosis and other chronic diseases (571) & 36 & 19.22 & 1.87 & 1.31 to 2.59 \\
\hline Injury and poisoning (800-999) & 35 & 26.34 & 1.33 & 0.93 to 1.85 \\
\hline
\end{tabular}

deaths, SMR 1.44, CI 1.32 to 1.56) and all cancers (141 deaths, SMR 1.27, CI 1.07 to 1.50). Among cancer deaths, a relevant excess was found for cancer of the liver (24 deaths, SMR 4.19, CI 2.68 to 6.23 ). Increased mortality was also observed for cancer of the lips, mouth, and pharynx (8 deaths, SMR 2.10, CI 0.91 to 4.14), oesophagus (6 deaths, SMR 2.19, CI 0.8 to 4.77), and-based on a few deaths-for bone and articular cartilage ( 2 deaths, SMR 2.22, CI 0.27 to 8.04 ), and connective tissue ( 1 death, SMR 5.04, CI 0.13 to 28.1). No increase was found for lung cancer mortality ( 32 deaths, SMR 0.97 , CI 0.67 to 1.37 ) or bladder cancer ( 5 deaths, SMR 1.08, CI 0.35 to 2.53). A lower than expected mortality from diseases of the circulatory system was detected (126 deaths, SMR 0.88, CI 0.73 to 1.05). Almost $50 \%$ of the excess mortality observed for all causes was due to non-malignant respiratory diseases (108 deaths, SMR 4.04, CI 3.31 to 4.87 ), especially silicosis (79 deaths, SMR 66.39, CI 52.56 to 82.74 ), listed as a leading cause of death. Sixteen of 79 deaths from silicosis $(20 \%)$ were also affected by pulmonary tuberculosis (ICD-9 11.9), an infectious disease that was listed as a main cause of death for two workers (data not shown in the tables). Silicosis was also mentioned in 21 death certificates as a disease involved in the process leading to death, in those who died for other causes, resulting in a total number of 100 deceased workers out of 541 deaths (18.5\%) with this occupational lung disease listed in the death certificate. All 79 deaths from silicosis occurred in workers hired before 1967 when rice husks replaced siliceous sand in the graphitisation process (data not shown in the tables). A higher than expected mortality was detected for diseases of the digestive system (49 deaths, SMR 1.63, CI 1.20 to 2.15), particularly cirrhosis and other chronic diseases of the liver (36 deaths, SMR 1.87, CI 1.31 to 2.59 ).

Comparison with regional death rates for the follow up period 1970 to 97 (data not shown in the tables) resulted in slightly lower SMRs for all causes (410 deaths, SMR 1.13, CI 1.02 to 1.25 ), all cancers ( 126 deaths, SMR 0.99 , CI 0.83 to 1.18), liver cancer (20 deaths, SMR 2.57, CI 1.57 to 3.97), silicosis (47 deaths, SMR 57.32, CI 42.11 to 76.22 ), and cirrhosis and other chronic diseases of the liver (33 deaths, SMR 1.49, CI 1.03 to 2.09).

Examination of mortality from selected causes by age at hire (table 2 ) revealed excesses of all deaths in all age-at-hire groups and of all cancers (49 deaths, SMR 1.44, CI 1.07 to 1.91 ), in workers hired at age $<25$ years. Excess mortality from cancer of the liver was detected in all groups of age at hire, with SMRs ranging between 3.60 (age at hire $>34$ years) and 4.66 (age at hire 25-34 years). The SMR for silicosis was twice as high in workers hired at a young age ( $<25$ years: SMR 81.79, CI 52.4 to 121.7 ; and 25-34 years: SMR 82.73, CI 57.9 to 114.5 ), than in workers hired at $>34$ years of age (SMR 41.18, CI 24.8 to 64.3).

Table 3 shows the SMRs for selected causes by age at death. Overall mortality was increased in all groups of age at death, with detected SMRs ranging between 1.21 and 1.86 in the age groups $>59$ years and 45-59 years, respectively. Mortality from cancer of the liver showed a fourfold increase in the age-at-death groups 45 to 59 years ( 7 deaths, SMR 4.46, CI 1.79 to 9.19 ), and $>59$ years ( 16 deaths, SMR 4.0, CI 2.29 to 6.50$)$. Excess mortality for silicosis was much higher in workers aged $<45$ years at death ( 10 deaths, SMR 333.3, CI 159.8 to 613 ) and those aged $45-59$ years ( 39 deaths, SMR 121.9 , CI 86.66 to 166.6). Despite these excesses occurring at a young age, mortality from silicosis remained 36 times higher than expected in the age-at-death group $>59$ years (30 deaths, SMR 35.71, CI 24.1 to 50.9). Mortality from liver cirrhosis was more than double compared to the expected figure in the age-at-death group 45-59 years ( 17 deaths, SMR 2.36, CI 1.37 to 3.78 ) and almost double in the oldest age group (11 deaths, SMR 1.89, CI 0.97 to 3.39).

Decreasing SMRs with increasing time since first employment (table 4$)$ were observed for all causes $\left(\chi^{2}\right.$ for trend $\left.\left(\chi_{\mathrm{t}}^{2}\right)=11.1, \quad \mathrm{p}=0.0009\right)$ and non-malignant respiratory diseases, including silicosis $\left(\chi_{\mathrm{t}}^{2}=18.9, \mathrm{p}=0.00001\right.$; and $\chi_{\mathrm{t}}^{2}=20.1, \mathrm{p}=0.00001$, respectively). Increased mortality from cancer of the liver was detected only after 10 years since first employment: two deaths occurred in the group 
Table 2 Mortality from selected causes by age at hire

\begin{tabular}{|c|c|c|c|c|c|c|c|c|c|}
\hline \multirow[b]{3}{*}{ Cause of death (ICD 9) } & \multicolumn{9}{|c|}{ Age at hire } \\
\hline & \multicolumn{3}{|c|}{$<25$ years } & \multicolumn{3}{|c|}{$25-34$ years } & \multicolumn{3}{|c|}{$>34$ years } \\
\hline & 0 & SMR & $95 \% \mathrm{Cl}$ & 0 & SMR & $95 \% \mathrm{Cl}$ & 0 & SMR & $95 \% \mathrm{Cl}$ \\
\hline All causes (001-999) & 148 & 1.39 & 1.18 to 1.63 & 219 & 1.62 & 1.41 to 1.85 & 174 & 1.30 & 1.11 to 1.50 \\
\hline Malignant neoplasms (140-208) & 49 & 1.44 & 1.07 to 1.91 & 50 & 1.22 & 0.91 to 1.61 & 42 & 1.16 & 0.84 to 1.57 \\
\hline Cancer of the liver (155) & 8 & 4.18 & 1.80 to 8.23 & 10 & 4.66 & 2.23 to 8.56 & 6 & 3.60 & 1.32 to 7.84 \\
\hline Lung cancer 162 & 8 & 0.76 & 0.33 to 1.50 & 12 & 0.97 & 0.50 to 1.69 & 12 & 1.20 & 0.62 to 2.10 \\
\hline Silicosis $(500,502)$ & 24 & 81.79 & 52.4 to 121.7 & 36 & 82.73 & 57.9 to 114.5 & 19 & 41.18 & 24.8 to 64.3 \\
\hline $\begin{array}{l}\text { Liver cirrhosis and other chronic } \\
\text { diseases (571) }\end{array}$ & 8 & 1.29 & 0.56 to 2.54 & 17 & 2.36 & 1.37 to 3.78 & 11 & 1.89 & 0.97 to 3.39 \\
\hline
\end{tabular}

with 10 to 20 years since hire (SMR 4.8, CI .58 to 17.33) and 22 after $>19$ years since hire (SMR 4.21, CI 2.64 to 6.37). Mortality from cirrhosis and other chronic diseases of the liver showed a positive trend with time since first employment, with the highest SMR detected $>19$ years after hire $(29$ deaths, SMR 1.99, CI 1.33 to 2.86).

Mortality from selected causes by cumulative length of employment at the factory is set out in table 5. Mortality for all causes was increased in each category of length of employment with SMRs ranging between 1.38 and 1.50. SMR for malignant neoplasms increased moderately $\left(\chi_{\mathrm{t}}^{2}=13.3\right.$, $\mathrm{p}=0.0003$ ) with length of employment; the number of observed deaths was higher than expected for $>19$ years of employment (86 deaths, SMR 1.54, CI 1.24 to 1.91). Mortality from cancer of the lips, mouth, and pharynx and oesophageal cancer increased also with length of employment. Higher SMRs were detected in workers with the longest employment at the plant ( $>19$ years): lips, mouth, and pharynx (6 deaths, SMR 3.16, CI 1.16 to 6.88), and oesophageal cancer ( 5 deaths, SMR 3.58, CI 1.16 to 8.35). Despite these excesses, none of these cancer sites showed a clear trend with duration of employment. SMRs for liver cancer increased $\left(\chi_{\mathrm{t}}^{2}=6.23\right.$, $\mathrm{p}=0.01$ ), with length of employment up to an SMR of 5.83 ( 18 deaths, CI 3.46 to 9.22 ) for workers with $>19$ years of employment at the plant. Comparison with regional death rates confirmed the positive trend with length of employment, with an SMR of 3.73 (2.13 to 6.05) in workers with $>19$ years of employment (data not shown). Observed deaths from lung and bladder cancers were never in excess and failed to show a clear trend with duration of employment. Mortality from cardiovascular diseases was lower than expected at all levels of duration of employment while mortality from non-malignant respiratory diseases was always higher. SMRs for respiratory system diseases decreased with increasing length of employment, a decrease that was largely due to the downward trend detected in excess mortality from silicosis $\left(\chi_{\mathrm{t}}^{2}=19.5, \mathrm{p}=0.00001\right)$. Mortality from cirrhosis and other chronic diseases of the liver increased with length of employment $\left(\chi_{t}^{2}=1.97\right.$, $\mathrm{p}=0.16)$; the largest excess was detected in workers with $>19$ years of employment at the plant (20 deaths, SMR 2.23, $\mathrm{CI}=1.36$ to 3.44$)$.

To investigate the role of occupational exposure to liver toxicants in the reported excess mortality for liver diseases, SMR analysis was restricted to workers actively employed for at least one year during the manufacture of Karbate products which started in 1959 and ended in 1976 (data not shown in tables). Twenty three of 24 deaths from liver cancer (96\%) occurred in this subcohort. Mortality from liver cancer was significantly increased with respect to Italian (SMR 4.30, 2.73 to 6.45 ) or regional death rates (SMR 3.03, 1.92 to 4.54$)$. Twenty of 23 deaths from liver cancer $(87 \%)$ occurred after 10 years since 1959 for those hired before 1959, or after 10 years since hire for workers hired between 1959 and 1976. Mortality for liver cancer was significantly increased in workers with $\geqslant 10$ years duration of employment (SMR 3.11, 1.78 to 5.05) compared to regional rates. Mortality from cirrhosis and other chronic diseases of the liver was also increased in this subcohort (SMR 1.57, 1.09 to 2.21 ) in comparison with regional death rates.

\section{DISCUSSION}

This historical cohort study of workers in a graphite electrode production plant in Italy showed an excess of mortality for all causes (SMR 1.44), all cancers (SMR 1.27), liver cancer (SMR 4.19 ), and diseases of the respiratory system (SMR 4.04), mainly silicosis (SMR 66.39), and digestive system diseases (SMR 1.63), specifically cirrhosis and other chronic diseases of the liver (SMR 1.87).

Mortality from cardiovascular diseases was lower than expected (SMR 0.88), suggesting the existence of a residual healthy worker effect.

Table 3 Mortality from selected causes by age at death

\begin{tabular}{|c|c|c|c|c|c|c|c|c|c|}
\hline \multirow[b]{3}{*}{ Cause of death (ICD 9) } & \multicolumn{9}{|c|}{ Age at death } \\
\hline & \multicolumn{3}{|c|}{$<\mathbf{4 5}$ years } & \multicolumn{3}{|c|}{$45-59$ years } & \multicolumn{3}{|c|}{$>59$ years } \\
\hline & $\overline{0}$ & SMR & $95 \% \mathrm{Cl}$ & $\overline{0}$ & SMR & $95 \% \mathrm{Cl}$ & 0 & SMR & $95 \% \mathrm{Cl}$ \\
\hline All causes (001-999) & 58 & 1.83 & 1.39 to 2.37 & 192 & 1.86 & 1.61 to 2.14 & 291 & 1.21 & 1.07 to 1.35 \\
\hline Malignant neoplasms (140-208) & 2 & 0.33 & 0.04 to 1.21 & 54 & 1.55 & 1.16 to 2.02 & 85 & 1.21 & 0.97 to 1.50 \\
\hline Cancer of the liver (155) & 1 & 7.69 & 0.19 to 42.86 & 7 & 4.46 & 1.79 to 9.19 & 16 & 4.00 & 2.29 to 6.50 \\
\hline Lung cancer (162) & 0 & 0.00 & 0.00 to 2.66 & 17 & 1.51 & 0.88 to 2.42 & 15 & 0.73 & 0.41 to 1.21 \\
\hline $\begin{array}{l}\text { Diseases of the respiratory system } \\
(460-519)\end{array}$ & 10 & 9.09 & 4.36 to 16.72 & 45 & 9.05 & 6.60 to 12.12 & 53 & 2.56 & 1.92 to 3.35 \\
\hline Silicosis $(500,502)$ & 10 & 333.33 & 159.8 to 613.0 & 39 & 121.88 & 86.66 to 166.6 & 30 & 35.71 & 24.10 to 50.9 \\
\hline $\begin{array}{l}\text { Liver cirrhosis and other chronic } \\
\text { diseases (571) }\end{array}$ & 8 & 1.29 & 0.56 to 2.54 & 17 & 2.36 & 1.37 to 3.78 & 11 & 1.89 & 0.97 to 3.39 \\
\hline
\end{tabular}


Table 4 Mortality from selected causes by time since first employment

\begin{tabular}{|c|c|c|c|c|c|c|c|c|c|}
\hline \multirow[b]{3}{*}{ Cause of death (ICD 9) } & \multicolumn{9}{|c|}{ Time since first employment } \\
\hline & \multicolumn{3}{|c|}{$<10$ years } & \multicolumn{3}{|c|}{$10-19$ years } & \multicolumn{3}{|c|}{$>19$ years } \\
\hline & 0 & SMR & $95 \% \mathrm{Cl}$ & 0 & SMR & $95 \% \mathrm{Cl}$ & 0 & SMR & $95 \% \mathrm{Cl}$ \\
\hline All causes (001-999) & 38 & 1.91 & 1.35 to 2.62 & 96 & 1.89 & 1.53 to 2.31 & 407 & 1.33 & 1.21 to 1.47 \\
\hline All malignant neoplasms (140-208) & 4 & 1.01 & 0.27 to 2.57 & 11 & 0.81 & 0.40 to 1.45 & 126 & 1.35 & 1.12 to 1.61 \\
\hline Lips, mouth and pharynx (140-149) & 1 & 7.02 & 0.18 to 39.12 & 1 & 1.78 & 0.05 to 9.94 & 6 & 1.93 & 0.71 to 4.21 \\
\hline Oesophagus (150) & - & 0.00 & 0.00 to 37.92 & - & 0.00 & 0.00 to 8.38 & 6 & 2.61 & 0.96 to 5.68 \\
\hline Liver (155) & - & 0.00 & 0.00 to 34.78 & 2 & 4.80 & 0.58 to 17.33 & 22 & 4.21 & 2.64 to 6.37 \\
\hline Lung (162) & 2 & 2.37 & 0.29 to 8.57 & 5 & 1.35 & 0.44 to 3.14 & 25 & 0.88 & 0.57 to 1.3 \\
\hline Bladder (188) & - & 0.00 & 0.00 to 40.07 & - & 0.00 & 0.00 to 8.08 & 5 & 1.20 & 0.39 to 2.8 \\
\hline Diseases of the circulatory system (390-459) & 4 & 0.86 & 0.23 to 2.20 & 23 & 1.48 & 0.94 to 2.22 & 99 & 0.81 & 0.65 to 0.98 \\
\hline $\begin{array}{l}\text { Diseases of the respiratory system } \\
(460-519)\end{array}$ & 9 & 9.52 & 4.35 to 18.06 & 22 & 7.73 & 4.84 to 11.7 & 77 & 3.35 & 2.65 to 4.19 \\
\hline Silicosis $(500,502)$ & 8 & 189.10 & 81.64 to 372.6 & 19 & 121.02 & 72.8 to 188.9 & 52 & 52.49 & 39.2 to 68.8 \\
\hline $\begin{array}{l}\text { Liver cirrhosis and other chronic diseases } \\
\text { (571) }\end{array}$ & 1 & 0.92 & 0.02 to 5.10 & 6 & 1.69 & 0.62 to 3.67 & 29 & 1.99 & 1.33 to 2.86 \\
\hline
\end{tabular}

Mortality from lung (SMR 0.97) and bladder cancers (SMR 1.08 ) was very close to the expected figure. These findings are partially in agreement with those from previous studies conducted in graphite electrode production workers in the USA, France, Sweden, and Japan, ${ }^{1-5}$ and from an Italian study which revealed an excess of deaths for non-malignant respiratory diseases (SMR 1.58), but no excess of deaths for all cancers, lung or bladder cancers. ${ }^{6}$ Since our study failed to detect a clear duration of employment-response relation for lung and bladder cancers, that are known to be linked to cigarette smoking habits and coal tar and coal tar pitch volatiles (that is, polycyclic aromatic hydrocarbons) in the workplace, we can conclude, with a good degree of confidence, against the possible role of these two factors in the observed excess mortality from all cancers. The discrepancies between our findings and those reported by other studies among carbon graphite workers, ${ }^{1-5}$ may be also attributed to differences in the manufacturing process resulting in different exposure to toxic agents, including air levels of coal tar pitch volatile, PAH, and quartz. ${ }^{15}$ Exposure to PAH may differ considerably between and within graphite electrode plant. Benzo[a]pyrene (BaP) mean levels have been reported to vary between $0.46 \mu \mathrm{g} / \mathrm{m}^{3}$ in one French plant, ${ }^{2}$ $10 \mu \mathrm{g} / \mathrm{m}^{3}$ in a Japanese plant, ${ }^{5}$ and $40 \mu \mathrm{g} / \mathrm{m}^{3}$ in a Swedish plant, ${ }^{3}$ with higher exposure entailed at the impregnation $\left(5.6-40 \mu \mathrm{g} / \mathrm{m}^{3}\right)^{2}{ }^{3}$ than at the baking workshop $(0.78-1.3 \mu \mathrm{g} /$ $\left.\mathrm{m}^{3}\right) .{ }^{23}$ Therefore, given the lack of data on workers' specific exposure to $\mathrm{PAH}$, our study may have failed to detect the increased lung cancer risk reported by other studies of graphite workers ${ }^{3-5}$ due to a dilution of the lung cancer risk (estimated for the entire cohort). Furthermore, it is worth noting that in a recent study ${ }^{12}$ exposure to PAH in a carbon electrode manufacturing plant did not result in a measurable effect at the DNA level in blood lymphocytes, whereas studies on PAH-DNA adducts among workers exposed to PAH in electrode paste, primary aluminium, coke oven, and graphite electrode plants provided contrasting results. ${ }^{13-15}$ Moreover, the high mortality from silicosis (SMR 66.39) may have acted as a strong competitive cause of death and, at least partly, explain the lack of increased lung cancer risk. Forty nine of 79 deaths from silicosis (62\%) occurred among workers aged $<45$ years (SMR 333.3) and 45-59 years at death (SMR 121.88). These findings reflect the role of occupational exposure to high level of silica dust in the development of severe silicosis leading to premature death (that is, $<60$ years of age). Indeed, death rates for lung cancer in Italy peaked after 60 years of age in 1955-84, ${ }^{16}$ and afterwards. ${ }^{17}$

The excess of deaths from primary cancer of the liver (SMR 4.19), and for cirrhosis and other chronic diseases of the liver (SMR 1.87), may reflect a higher mortality for both liver cancers (SMR 1.74) and chronic liver diseases (SMR 1.65) reported for the local male population of the area where the plant is located. ${ }^{9}$ In comparison with regional death rates, both mortality from liver cancer (SMR 2.57) and liver cirrhosis (SMR 1.47) remained significantly increased, although the excess for liver cirrhosis was compatible with

Table 5 Mortality from selected causes by cumulative length of employment

\begin{tabular}{|c|c|c|c|c|c|c|c|c|c|}
\hline \multirow[b]{3}{*}{ Cause of death (ICD 9) } & \multicolumn{9}{|c|}{ Length of employment } \\
\hline & \multicolumn{3}{|c|}{$<10$ years } & \multicolumn{3}{|c|}{$10-19$ years } & \multicolumn{3}{|c|}{$>19$ years } \\
\hline & 0 & SMR & $95 \% \mathrm{Cl}$ & O & SMR & $95 \% \mathrm{Cl}$ & 0 & SMR & $95 \% \mathrm{Cl}$ \\
\hline All causes (001-999) & 105 & 1.48 & 1.21 to 1.79 & 192 & 1.50 & 1.30 to 1.73 & 244 & 1.38 & 1.21 to 1.56 \\
\hline Malignant neoplasms (140-208) & 8 & 0.39 & 0.17 to 0.77 & 47 & 1.35 & 0.99 to 1.79 & 86 & 1.54 & 1.24 to 1.91 \\
\hline Lips, mouth, and pharynx (140-149) & 1 & 1.36 & 0.03 to 7.60 & 1 & 0.85 & 0.02 to 4.75 & 6 & 3.16 & 1.16 to 6.88 \\
\hline Oesophagus (150) & 0 & 0.00 & 0.00 to 6.24 & 1 & 1.17 & 0.03 to 6.49 & 5 & 3.58 & 1.16 to 8.35 \\
\hline Liver (155) & 0 & 0.00 & 0.00 to 2.92 & 6 & 3.71 & 1.36 to 8.08 & 18 & 5.83 & 3.46 to 9.22 \\
\hline Lung (162) & 3 & 0.51 & 0.10 to 1.48 & 10 & 1.02 & 0.49 to 1.88 & 19 & 1.11 & 0.67 to 1.73 \\
\hline Bladder (188) & 0 & 0.00 & 0.00 to 4.18 & 2 & 1.35 & 0.16 to 4.89 & 3 & 1.24 & 0.26 to 3.63 \\
\hline Diseases of the circulatory system (390-459) & 21 & 0.92 & 0.57 to 1.41 & 42 & 0.83 & 0.60 to 1.12 & 63 & 0.90 & 0.69 to 1.15 \\
\hline $\begin{array}{l}\text { Diseases of the respiratory system } \\
(460-519)\end{array}$ & 28 & 6.82 & 4.53 to 9.86 & 40 & 4.13 & 2.95 to 5.62 & 40 & 3.09 & 2.20 to 4.20 \\
\hline Silicosis $(500,502)$ & 27 & 138.36 & 91.18 to 201.1 & 29 & 70.55 & 47.25 to 101.3 & 23 & 39.4 & 24.98 to 59.12 \\
\hline $\begin{array}{l}\text { Liver cirrhosis and other chronic diseases } \\
\text { (571) }\end{array}$ & 4 & 1.02 & 0.28 to 2.61 & 12 & 1.90 & 0.98 to 3.31 & 20 & 2.23 & 1.36 to 3.44 \\
\hline
\end{tabular}

O, observed deaths; SMR, standardised mortality ratio point estimate; $95 \% \mathrm{Cl}, 95 \%$ confidence interval of the SMR. 
the increased local mortality. ${ }^{9}$ In spite of the fact that previous studies conducted in this area ${ }^{18}{ }^{19}$ have reported that about $90 \%$ of liver cancer cases were attributable to hepatitis $\mathrm{B}$ or $\mathrm{C}$ virus infections, heavy alcohol intake, or a combination of both, the increased SMR for liver cancer detected by the study may also be attributed, at least partly, to occupational exposures that may have occurred at the plant. In fact, in the entire cohort, all liver cancer cases occurred after 10 years since hire, in the latency strata $10-19$ and $>19$ years since first employment (SMR 4.80 and 4.21, respectively), and in workers with $10-19$ and $>19$ years duration of employment (SMR 3.71 and 5.83, respectively). This findings were confirmed when regional rates were used to calculate expected deaths for the entire cohort (SMR 2.57), and when SMR analysis was restricted to the subcohort of workers ever employed for at least one year during the manufacture of Karbate products (SMR 2.71 and SMR 3.11 in workers with $\geqslant 10$ years of employment). Among the epidemiological studies of carbon products manufacturing workers, ${ }^{1-6}$ two reported lower than expected mortality from liver cancer, ${ }^{56}$ two did not report SMR estimates for liver cancer, ${ }^{14}$ and one detected a standardised incidence ratio (SIR) of 4.35 based on one incident case. ${ }^{3}$ Only one study mentioned exposure to furfuryl alcohol and furfural for 337 workers employed at two Union Carbide Corporation's facilities in the USA. ${ }^{1}$ Furfural $\left(\mathrm{C}_{5} \mathrm{H}_{4} \mathrm{O}_{2}\right)$, a precursor used in the manufacture of furfuryl alcohol and furan resins, is absorbed by all routes of exposure. Liver is the primary target for toxicity in rats and mice. Gavage studies have shown a statistically significant increased incidence of hepatocellular adenomas and carcinomas in B6C3F1 male mice, hepatocellular adenomas in F344/N female rats, and bile duct dysplasias and cholangiocarcinomas in F344/N male rats. ${ }^{20}$ Therefore, we cannot rule out the possibility that occupational exposure to chemical compounds used between 1959 and 1976 during the manufacture of Karbate products, to some extent, may explain the observed excess deaths from liver cancer, although lifestyle factors, viral infections, and chance may have played a role.

The significant excess mortality from non-malignant respiratory tract diseases (SMR 4.04) was mainly attributable to the excess deaths from silicosis (SMR 66.39). The excess was confirmed when regional death rates were used to compute expected deaths (SMR 57.32). Both siliceous sands and graphite had been widely used in the electrode manufacturing process in this factory at least until 1967 when siliceous sands were replaced with rice husks. The role of heavy exposure to silica dusts is also supported by the lack of deaths from silicosis in workers hired after 1967 despite a follow up period of 30 years (1967-97). The dramatic excess mortality from silicosis observed in workers hired at a young age-that is, age at hire $<25$ (SMR 81.79) and 25-34 years (SMR 82.73)—supports the hypothesis that the disease may be causally related to a relevant exposure occurring during their employment at the plant. An excess number of pneumoconiosis cases has been reported among carbon or graphite electrode workers, ${ }^{21}{ }^{22}$ and they have been attributed mostly to silica dust and asbestos in the work environment. Furthermore, graphite has also been reported as a cause of pneumoconiosis, ${ }^{23}$ with cases detected among graphite mine workers. ${ }^{24}$ The increased mortality from silicosis detected among these workers has not been reported by other epidemiological studies. ${ }^{1-6}$ However, a Swedish ${ }^{3}$ and an Italian ${ }^{6}$ cohort study showed an excess mortality from nonmalignant respiratory diseases that was inversely related with duration of employment. ${ }^{6}$ The excess mortality from silicosis was inversely related to duration as well as to time since first employment at the plant and age at death. These downward trends may reflect the effect of silica dust exposure in susceptible workers who developed severe silicosis shortly after they were employed at the plant (SMR 138.36 for workers employed $<10$ years), and who died from it at a young age (SMR 333, age at death $<45$ years). A possible explanation for the observed excess is that mortality from silicosis was over-reported in the cohort. However, examination of mortality from respiratory tract diseases other than silicosis showed a moderate increase (29 deaths, SMR 1.13, CI 0.81 to 1.55 , data not shown), excluding the possibility of a serious over-reporting bias. Moreover, 47 of $79(60 \%)$ workers who died from silicosis received compensation for silicosis from the Italian National Institute of Insurance Against Accidents at Work (INAIL) on the basis of pathological or postmortem diagnosis. Therefore, although a possible role of exposure to silica dusts outside the factory cannot be completely excluded, these findings support the causal role of exposure to silica dusts at the plant in the observed excess mortality from silicosis.

The main limitation of this study, as with most mortality studies among carbon or graphite electrode workers, is the lack of historical data on workers' specific job titles, their specific activities inside the factory, and historical industrial hygiene data which have precluded any exposure specific classification of workers and the computation of exposure specific SMRs. Therefore, non-differential misclassification of exposure may have occurred, resulting in dilution of the risk of death due to specific occupational exposure(s). Furthermore, a possible underestimation of the risk of death from cancer due to occupational exposure in this cohort may also have occurred because of competing mortality and healthy worker effect, the latter acting mainly in its exposure related susceptible worker survivor component effect, ${ }^{25}$ resulting in differential survival of workers with different risks of disease. ${ }^{26}$

In conclusion, we found a dramatic excess of deaths for silicosis, which is compatible with the occupational exposure to silica dusts that occurred at the plant before 1967. We also found a high mortality from liver cancer and other liver chronic diseases. Although this may be due to lifestyle factors, mortality for liver cancer is higher than that reported in the general population in the area, suggesting a possible role of occupational exposures to chemicals that may have been experienced between 1959 and 1976 during the manufacture of Karbate products.

\section{ACKNOWLEDGEMENTS}

The authors are grateful to Prof. Benedetto Terracini for his comments on a preliminary analysis of the data.

\section{Authors' affiliations}

D F Merlo, M Ceppi, Environmental Epidemiology and Biostatistics, Istituto Nazionale per la Ricerca sul Cancro, Genoa, Italy

S Garattini, Local Health Unit of Brescia, Italy

U Gelatti, C Simonati, L Covolo, F Donato, Chair of Hygiene, University of Brescia, Italy

\section{REFERENCES}

1 Teta MJ, Ott MG, Schnatter AR. Population based mortality surveillance in carbon products manufacturing plants. Br J Ind Med 1987;44:344-50.

2 Moulin JJ, Wild P, Mur JM, et al. Risk of lung, larynx, pharynx and buccal cavity cancers among carbon electrode manufacturing workers. Scand J Work Environ Health 1989;15:30-7.

3 Gustavsson P, Bellander T, Hohansson L, et al. Surveillance of mortality and cancer incidence among Swedish graphite electrode workers. Environ Res 1995;70:7-10.

4 Boffetta P, Jourenkova N, Gustarsson P. Cancer risk from occupational and environmental exposure to polycyclic aromatic hydrocarbons. Cancer Causes Control 1997;8:444-72.

5 Mori I. Cancer mortality among man-made graphite electrode manufacturing workers: results of a 38 year follow. Occup Environ Med 2002;59:473-80. 
6 Donato F, Monarca S, Marchionna G, et al. Mortality from cancer and chronic respiratory diseases among workers who manufacture carbon electrodes. Occup Environ Med 2000;57:484-7.

7 International Agency for Research on Cancer (IARC). Overall evaluations of carcinogenicity: an updating of IARC Monographs, volumes 1-42. IARC Monographs on the evaluation of carcinogenic risks to humans, suppl 7. Lyon, IARC, 1987

8 International Agency for Research on Cancer (IARC). Silica, silicates, coal dust and para-aramid fibrils, volume 68. IARC Monographs on the evaluation of carcinogenic risks to humans. Lyon, IARC, 1997.

9 Pasquale L, Donato F, Chiesa R, et al. La mortalità nell'Azienda Sanitaria Locale di Vallecamonica - Sebino (Brescia) dal 1980 al 1997: I'impatto del fumo di tabacco, del consumo di alcol e degli incidenti da traffico. Ann lg 2001;13:49-60.

10 Breslow NE, Day NE. Statistical methods in cancer research; vol II (The design and analysis of cohort studies). IARC Scientific Publications, no 82. Lyon: International Agency for Research on Cancer, 1987.

11 StataCorp. Stata Statistical Software: release 7.0, 1999; Stata Corporation, College Station, Texas.

12 Van Delft JH, Steenwinkel MJ, Van Asten JG, et al. Monitoring of occupationa exposure to polycyclic aromatic hydrocarbons in a carbon-electrode manufacturing plant. Ann Occup Hyg 1998;42:105-14.

13 Van Schooten FJ, Jongeneelen FJ, Hillebrand MJ et al. Polycyclic aromatic hydrocarbon-DNA adducts in white blood cell DNA and 1-hydroxypyrene in the urine from aluminum workers: relation with job category and synergistic effect of smoking. Cancer Epidemiol Biomarkers Prev 1995;4:69-77.

14 Ovrebo S, Haugen A, Fieldstad PE, et al. Biological monitoring of exposure to polycyclic aromatic hydrocarbons in an electrode paste plant. J Occup Med 1994;36:303-10

15 Marczynski B, Rihs HP, Rossbach B, et al. Analysis of 8-oxo-7, 8-dihydro-2" deoxyguanosine and DNA strand breaks in white blood cells of occupationally exposed workers: comparison with ambient monitoring, urinary metabolites and enzyme polymorphisms. Carcinogenesis 2002;23:273-81.

16 La Vecchia C, Negri E, Decarli A, et al. Cancer mortality in Italy: an overview of age-specific and age-standardised trends from 1955 to 1984 . Tumori 1990;76:87-166.

17 Decarli A, La Vecchia C, Cislaghi C, et al. Cancer mortality in Italy, 1994, and an overview of trends from 1955 to 1994 . Tumori 1998:84:312-34.

18 Chiesa R, Donato F, Tomasoni S, et al. Primary liver cancer in a high incidence area in North Italy: etiological hypotheses arising from routinely collected data. Eur J Epidemiol 1995;11:435-42.

19 Donato F, Tagger A, Chiesa R, et al. Hepatitis B and C virus infection, alcohol drinking and hepatocellular carcinoma: a case-control study in Italy. Hepatology 1997;26:579-84.

20 USA-National Toxicology Program. Toxicology and carcinogenesis studies of furfural (case no. 98-01-1) in F344/N rats and $\mathrm{B}^{\mathrm{F}} \mathrm{C} 3 \mathrm{~F}_{1}$ mice (gavage studies). Toxicology and Carcinogenesis Reports No. 382, 1990.

21 Petsonk EL, Storey E, Becker PE, et al. Pneumoconiosis in carbon electrode workers. J Occup Med 1988;30:887-91.

22 Valentino $M$, Scielzo R, Pisani $E$, et al. Chronic bronchitis risk in graphite electrode workers. Arch Scienze Lav 1988;4:99-103.

23 Hanoa R. Graphite pneumoconiosis. A review of etiologic and epidemiologic aspects. Scand J Work Environ Health 1983:9:303-14.

24 Uragoda GC. A cohort study of graphite workers in Sri Lanka. Occup Med (Lond) 1997;47:269-72.

25 Checkoway H, Pearce N, Crawford-Brown DJ. Research methods in occupational epidemiology: Monographs in Epidemiology and Biostatistics, Vol. 13. New York: Oxford University Press, 1989.

26 Arrighi HM, Hertz-Picciotto I. The evolving concept of the healthy worker survivor effect. Epidemiology 1994;5:188-96. 